\title{
SISTEM INFORMASI PENGELOLAAN ARSIP STATIS PADA BADAN ARSIP DAN PERPUSTAKAAN PROVINSI JAWA TENGAH MENGGUNAKAN VECTOR SPACE MODEL
}

\author{
Silmi Kafatan, Djalal Er Riyanto, Ragil Saputra \\ Jurusan Ilmu Komputer / Informatika Fakultas Sains dan Matematika Universitas Diponegoro \\ Email : ichilme@gmail.com
}

\begin{abstract}
ABSTRAK
Badan Arsip dan Perpustakaan (Arpus) Provinsi Jawa Tengah adalah salah satu lembaga pemerintah yang berkewajiban menjaga dan melestarikan arsip statis yang berada di tingkat provinsi. Salah satu upaya penyelamatan arsip dalam perspektif modern saat ini cenderung mengarah bagaimana memanfaatkan teknologi informasi untuk mengelola arsip. Sistem Informasi Pengelolaan Arsip Statis menggunakan vector space model merupakan sistem yang dapat memudahkan pengelolaan arsip statis, mampu diakses oleh siapa saja yang membutuhkan informasi kearsipan serta memberikan kemudahan dalam hal pencarian arsip yang relevan dengan kebutuhan pengguna sistem. Pada fungsi pencarian arsip, sistem menggunakan metode Term Frequency-Inverse Document Frequency (TFIDF) untuk memberikan bobot pada setiap indeks dari kata-kata (term) dan vector space model untuk mengukur kemiripan antara vektor dokumen dengan vektor kata kunci. Pada pengujian terdapat tiga besaran performansi yang dihitung yaitu Recall untuk menemukan seluruh dokumen yang relevan dalam koleksi dokumen, Precision untuk menemukan hanya dokumen yang relevan saja dalam koleksi dan Interpolated Recall Precision untuk mengukur performansi sistem dengan mempertimbangkan aspek keterurutan dokumen relevan. Sistem telah diuji pada 75 dokumen arsip dengan memasukkan 10 kata kunci yang berhubungan dengan dokumen arsip. Hasil pengujian menunjukkan nilai rata-rata recall sebesar $99 \%$ dan nilai rata-rata precision sebesar $36,4 \%$. Untuk nilai rata-rata interpolasi precision pada hasil penghitungan interpolasi antara recall dan precision sebesar $90,2 \%$.
\end{abstract}

Kata kunci : sistem informasi pengelolaan arsip statis, metode TF-IDF, vector space model.

\section{PENDAHULUAN}

Badan Arsip dan Perpustakaan (Arpus) Provinsi Jawa Tengah adalah salah satu lembaga pemerintah yang berkewajiban menjaga dan melestarikan arsip statis yang berada di tingkat provinsi. Pengelolaan arsip statis tersebut bukan hanya demi kepentingan lembaga semata, namun yang terpenting adalah untuk individu atau lembaga lain yang akan menggunakannya untuk berbagai keperluan seperti penelitian, kajian, pengembangan ilmu pengetahuan, dan lain sebagainya [13].

Selama ini penyimpanan arsip statis yang terdapat pada Badan Arpus Provinsi Jawa Tengah seperti arsip peninggalan Belanda masih berada dalam kotak-kotak penyimpanan kemudian datanya disimpan ke dalam Microsoft Access. Arsip peninggalan Belanda adalah arsip masa pemerintahan Hindia Belanda yang meliputi segala masalah yang menyangkut hubungan kepemerintahan dan kemasyarakatan antara pemerintah dan warga negara ataupun penduduk di wilayah Hindia Belanda saat itu. Mengingat arsip tersebut merupakan arsip yang mempunyai nilai sejarah dan rawan mengalamai kerusakan maka diperlukan upaya untuk menyelamatkan arsip tersebut.

Penyelamatan arsip dalam perspektif modern saat ini cenderung mengarah bagaimana memanfaatkan teknologi informasi untuk melestarikan arsip dalam jangka panjang. Salah satu upaya untuk menyelamatkan arsip yang direkomendasikan dalam berbagai seminar dan workshop yang diselenggarakan oleh organisasi internasional adalah digitalisasi.

Banyaknya jumlah arsip digital juga akan menimbulkan masalah dalam hal pencarian arsip. Pencarian arsip akan memerlukan waktu yang relatif lama. Semakin besar jumlah arsip yang dimiliki, maka kecepatan dan ketepatan perolehan atau temu kembali informasi arsip sangat penting bagi para pencari informasi karena tuntutan akan waktu. Pencarian 
berdasarkan query oleh pengguna sistem informasi diharapakan mampu menemukan koleksi dokumen yang relevan dengan kebutuhan pengguna sistem informasi.

Pengukuran tingkat kemiripan suatu dokumen dengan dokumen lainnya dapat dilakukan dengan mudah oleh manusia, tetapi pengukuran yang dilakukan secara otomatis oleh komputer akan membawa permasalahan tersendiri. Salah satu upaya untuk mengatasi permasalahan tersebut dengan membangun Information Retrieval System atau sistem temu kembali informasi. Tujuan dari sistem temu kembali informasi adalah untuk memenuhi kebutuhan informasi pengguna dengan meretrieve semua dokumen yang mungkin relevan, pada waktu yang sama me-retrieve sesedikit mungkin dokumen yang tidak relevan [8]. Proses pengukuran tingkat kemiripan antar dokumen dilakukan dengan membandingkan kata kunci dengan dokumen. Kata kunci yang digunakan didapat dari masukan pengguna sistem. Agar hasil pengukuran tingkat kemiripan dokumen dengan kata kunci mendapatkan hasil yang optimal, maka digunakan metode TF-IDF (Term Frequency - Inversed Document Frequency) untuk menghitung bobot dokumen dan VSM (Vector Space Model) untuk mencari nilai cosine (menghitung nilai cosinus sudut antara dua vektor) sebagai pengukur tingkat kemiripan antara dokumen dengan kata kunci yang dimasukkan oleh pengguna sistem [6].

\section{DASAR TEORI \\ Sistem Temu Kembali Informasi}

Information retrieval (IR) system atau sistem temu kembali informasi digunakan untuk menemukan kembali informasi-informasi yang relevan terhadap kebutuhan pengguna dari suatu kumpulan informasi secara otomatis. Salah satu aplikasi umum dari IR system adalah search engine atau mesin pencari yang terdapat pada jaringan internet. Pengguna dapat mencari halaman-halaman web yang dibutuhkannya melalui search engine [3].

Tujuan dari sistem temu kembali informasi yang ideal adalah [9]:

1) Menemukan seluruh dokumen yang relevan terhadap suatu query.
2) Hanya menemukan dokumen relevan saja, artinya tidak terdapat dokumen yang tidak relevan pada dokumen hasil pencarian.

Dua keadaan tersebut digunakan untuk menghitung performansi sistem temu kembali, yaitu recall dan precision.

Recall dinyatakan sebagai bagian dari dokumen relevan dalam dokumen yang ditemukan. Recall dapat dihitung dengan persamaan :

$\operatorname{Recall}(\mathrm{r})=\frac{\text { Jumlah dokumen relevan ditemukan }}{\text { Jumlah dokumen relevan dalam koleksi }} \ldots$ .(1)

Nilai recall tertinggi adalah 1 , yang berarti seluruh dokumen dalam koleksi berhasil ditemukan.

Precision dinyatakan sebagai bagian dokumen relevan yang ditemukan. Precision dapat dihitung dengan persamaan :

$\operatorname{Precision}(\mathrm{P})=$

Jumlah dokumen relevan ditemukan

Jumlah dokumen ditemukan

Nilai precision tertinggi adalah 1, yang berarti seluruh dokumen yang ditemukan adalah relevan.

Pengukuran recall dan precision ini merupakan perhitungan yang dilakukan terhadap kumpulan dokumen hasil pencarian (set based measure) secara keseluruhan. Pengukuran dengan menggunakan set based measure ini tidak dapat menggambarkan performansi sistem temu kembali informasi mengenai urutan dari dokumen relevan. Pengukuran performansi dengan mempertimbangkan aspek keterurutan atau rangking dapat dilakukan dengan melakukan interpolasi antara precision dan recall. Nilai rata-rata interpolated precision dapat mencerminkan urutan dari dokumen yang relevan pada perangkingan. Standar yang biasa digunakan adalah 11 standar tingkat recall, yaitu $r_{j} \in\{0.0,0.1,0.2,0.3,0.4,0.5,0.6,0.7,0.8,0.9$, $1.0\}$. Misalkan $\mathrm{r}_{\mathrm{j}}, \mathrm{j} \in\{0,1,2, \ldots .10\}$ adalah tingkat standar recall ke-j maka:

$\mathrm{P}\left(\mathrm{r}_{\mathrm{j}}\right)=\max \mathrm{r}_{\mathrm{j}} \leq \mathrm{r} \leq \mathrm{r}_{\mathrm{j}+1} \mathrm{P}(\mathrm{r})$

Aturan interpolasi adalah recall standard ke-j memiliki nilai interpolated precision 
sebesar maksimum precision pada recall yang lebih besar dari recall standard ke-j [9].

\section{Metode TF-IDF}

Term Frequency-Inverse Document Frequency adalah salah satu perhitungan bobot dari frekuensi kemunculan sebuah term pada dokumen. TF-IDF digunakan untuk mencari nilai bobot dari dokumen. TF-IDF akan memeriksa kemunculan tiap kata pada isi dokumen dari hasil tokenisasi, filtering dari kemuculan tiap kata pada isi dokumen. Adapun rumus yang digunakan untuk perhitungan TFIDF adalah sebagai berikut:

$$
\begin{aligned}
& \mathrm{IDF}=\log \frac{D}{d f} \ldots \ldots . . \\
& \mathrm{W}_{(\mathrm{d}, \mathrm{t})}=\mathrm{tf}_{(\mathrm{d}, \mathrm{t})} \mathrm{X} \operatorname{IDF}_{(\mathrm{t})}
\end{aligned}
$$

dimana IDF $=$ inversed document frequency

$\mathrm{D}=$ jumlah dokumen

$\mathrm{df}=$ banyak dokumen yang mengandung kata yang dicari

$\mathrm{d}=$ dokumen ke-d

$\mathrm{t}=$ kata ke-t dari kata kunci

$\mathrm{W}=$ bobot dokumen ke-d terhadap kata ke-t

tf $=$ banyaknya kata yang dicari pada sebuah dokumen

\section{Metode Vector Space Model}

Vector space model adalah suatu model yang digunakan untuk mengukur kemiripan antara suatu dokumen dengan suatu query. Pada model ini, query dan dokumen dianggap sebagai vektor-vektor pada ruang $n$-dimensi, di mana $n$ adalah jumlah dari seluruh term yang ada dalam leksikon. Leksikon adalah daftar semua term yang ada dalam indeks [6]. Ilustrasi Vector Space Model ditunjukkan pada gambar 1.
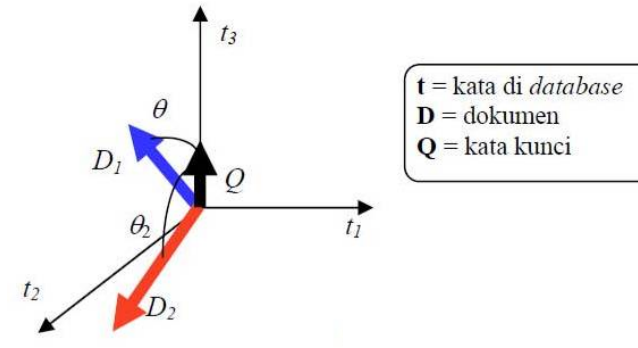

Gambar 1 Ilustrasi Vector Space

Metode vector space model menggunakan rumus untuk mencari nilai cosinus sudut antara dua vektor dari setiap bobot dokumen dan bobot dari kata kunci. Jika terdapat dua vektor dokumen $\mathrm{d}_{\mathrm{j}}$ dan query $\mathrm{q}$, serta term yang diekstrak dari koleksi dokumen maka nilai cosines antara $d_{j}$ dan $q$ dapat didefinisikan sebagai berikut :

$\operatorname{similarity}\left(\mathrm{d}_{\mathrm{j}}, \mathrm{q}\right)=\frac{d_{j} \cdot \mathrm{q}}{\left|d_{j}\right| \cdot|q|}=$

$\frac{\sum_{i=1}^{t} W_{i j} \cdot W_{i q}}{\sqrt{\sum_{i=1}^{t} W_{i j}^{2} \cdot \sum_{i=1}^{t} W_{i q}^{2}}} .(2.6)$

\section{ANALISIS DAN PERANCANGAN}

\section{Perspektif Sistem Lama}

Perspektif sistem lama Sistem Informasi Pengelolaan Arsip Statis dapat dilihat pada gambar 2 .

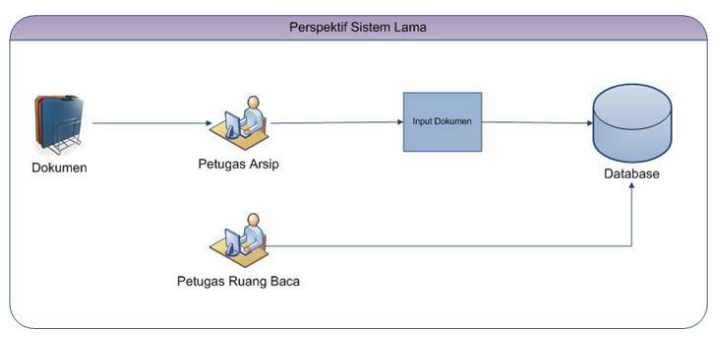

Gambar 2 Perspektif Sistem Lama

Sebagai lembaga kearsipan yang diberi kewenangan untuk mengatur, menyimpan, memelihara dan menyelamatkan arsip, Badan Arsip dan Perpustakaan Provinsi Jawa Tengah dituntut untuk dapat mengelola arsip dengan baik. Selama ini arsip statis seperti arsip peninggalan Belanda masih berada dalam kotakkotak penyimpanan, kemudian datanya disimpan ke dalam Microsoft Access. Berdasarkan sifat Microsoft access yang hanya sebatas single user diperlukan basis data yang dapat diakses pada saat yang bersamaan agar memudahkan petugas Badan Arsip dan Perpustakaan dalam pengelolaan data.

\section{Perspektif Sistem Baru}

Sistem Informasi Pengelolaan Arsip Statis dikembangkan sebagai sistem informasi berbasis web sehingga dapat diakses oleh siapa saja yang membutuhkan informasi tentang kearsipan. Sistem ini menggunakan sebuah web server yang terhubung ke sebuah basis data. Web 
server yang digunakan dalam sistem ini adalah apache dengan basis data mysql yang dapat diakses oleh beberapa pengguna dalam waktu yang bersamaan.

Secara garis besar perspektif Sistem Informasi Pengelolaan Arsip Statis dengan menggunakan Vector Space Model dapat dilihat pada gambar 3 .

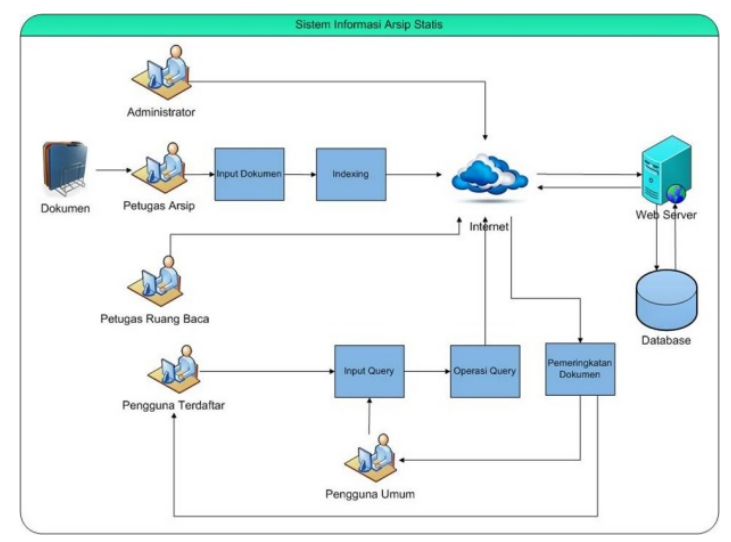

Gambar 3 Perspektif sistem baru

\section{Spesifikasi Perangkat Lunak}

Sistem Informasi Pengelolaan Arsip Statis memiliki beberapa kemampuan fungsionalitas seperti pada tabel 1 berikut ini:

Tabel 1 Spesifikasi Kebutuhan Perangkat Lunak

\begin{tabular}{|c|l|l|}
\hline NO & \multicolumn{1}{|c|}{ SRS ID } & \multicolumn{1}{|c|}{ Deskripsi } \\
\hline 1 & SRS-SIPA-F01 & Otentikasi pengguna \\
\hline 2 & SRS-SIPA-F02 & Manajemen data user \\
\hline 3 & SRS-SIPA-F03 & Manajemen data arsip \\
\hline 4 & SRS-SIPA-F04 & $\begin{array}{l}\text { Manajemen data } \\
\text { content }\end{array}$ \\
\hline 5 & SRS-SIPA-F05 & Manajemen data berita \\
\hline 6 & SRS-SIPA-F06 & $\begin{array}{l}\text { Manajemen transaksi } \\
\text { peminjaman arsip }\end{array}$ \\
\hline 7 & SRS-SIPA-F07 & $\begin{array}{l}\text { Melakukan pencarian } \\
\text { arsip }\end{array}$ \\
\hline
\end{tabular}

\section{Entity Relationship Diagram (ERD)}

Entity Relationship Diagram (ERD) Sistem Informasi Pengelolaan Arsip Statis terdiri dari sepuluh tabel di mana sembilan tabel berasal dari entitas dan satu tabel berasal dari relasi yaitu tabel Pinjam. ERD Sistem Informasi Pengelolaan Arsip Statis dapat dilihat pada gambar 4.

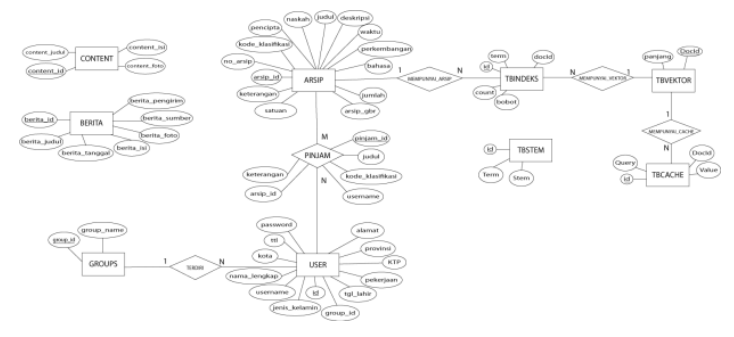

Gambar 4 ERD Sistem Informasi Pengelolaan Arsip Statis

\section{Pemodelan Fungsi}

Pemodelan fungsi terdiri dari Data Context Diagram (DCD) dan Data Flow Diagram (DFD). Untuk analisis pembangunan Sistem Informasi Pengelolaan Arsip Statis diperlukan DFD sampai level 2.

Sistem Informasi Pengelolaan Arsip Statis dapat dijelaskan melalui alur data context diagram seperti pada gambar 5 .

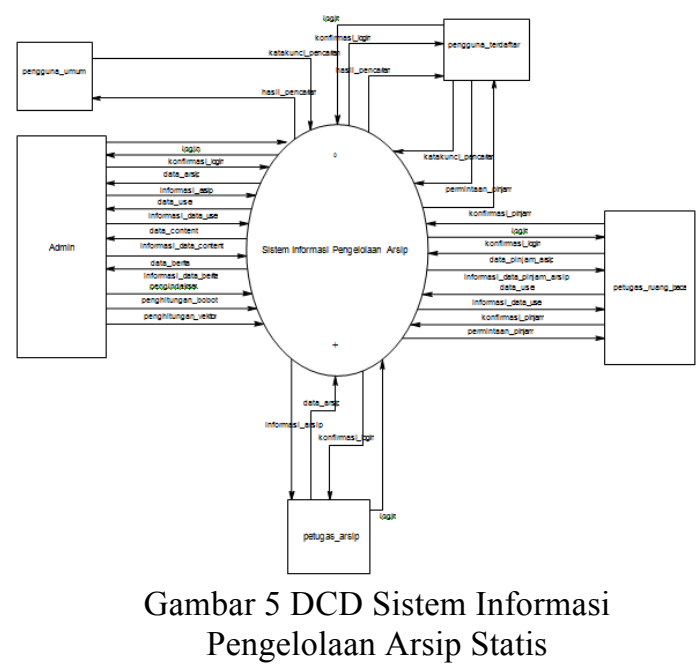

Pengguna sistem dapat dibedakan menjadi 5 tingkatan yaitu admin, petugas ruang baca, dan petugas arsip sebagai pengguna internal serta pengguna umum dan pengguna terdaftar sebagai pengguna eksternal. Penjelasan dari pengguna Sistem Informasi Pengelolaan Arsip adalah sebagai berikut :

1. Admin, yaitu pegawai Badan Arsip dan Perpustakaan Provinsi Jawa Tengah yang memiliki hak akses penuh terhadap sistem.

2. Pengguna umum, yaitu masyarakat atau lembaga lain yang ingin mengakses sistem informasi. 
3. Pengguna terdaftar, yaitu masyarakat atau lembaga lain yang sudah terdaftar menjadi anggota.

4. Petugas ruang baca, merupakan pegawai Badan Arsip dan Perpustakaan yang memiliki hak akses untuk melayani peminjaman arsip, mengelola data transaksi peminjaman arsip dan data pengguna terdaftar.

5. Petugas arsip, merupakan pegawai Badan Arsip dan Perpustakaan yang memiliki otoritas untuk mengelola data arsip statis seperti memasukkan, mengubah atau melakukan penghapusan arsip dalam basis data sistem.

DFD Level 1

Data Flow Diagram (DFD) Level 1 Sistem Informasi Pengelolaan Arsip Statis dapat dilihat seperti pada gambar 6 .

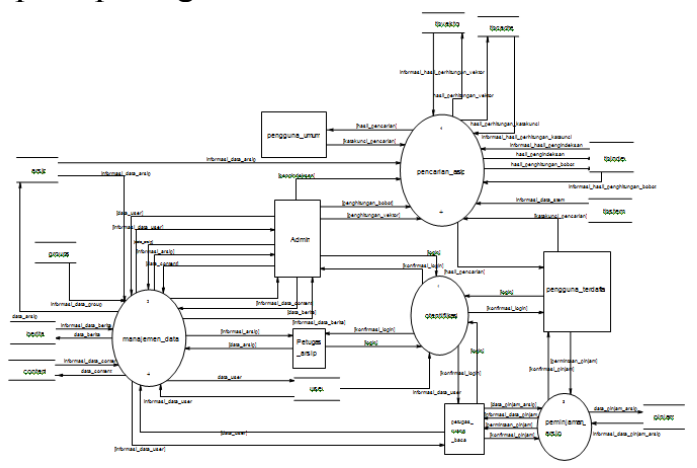

Gambar 6 DFD Level 1

Sistem secara umum dibagi menjadi lima buah proses yang berbeda. Proses-proses tersebut antara lain otentifikasi, manajemen data, pencarian arsip, peminjaman arsip dan stemming.

DFD Level 2

Data Flow Diagram (DFD) level 2 merupakan penjabaran proses-proses yang telah disebutkan pada level 1. Proses yang dijabarkan pada DFD level 2 ini adalah proses Manajemen Data dan proses Pencarian Arsip. Proses Manajemen Data dijabarkan menjadi proses Manajemen Data User, Manajemen Data Arsip, Manajemen Data Content, dan Manajemen Data Berita. DFD level 2 subproses Manajemen Data dapat dilihat pada gambar 7 .

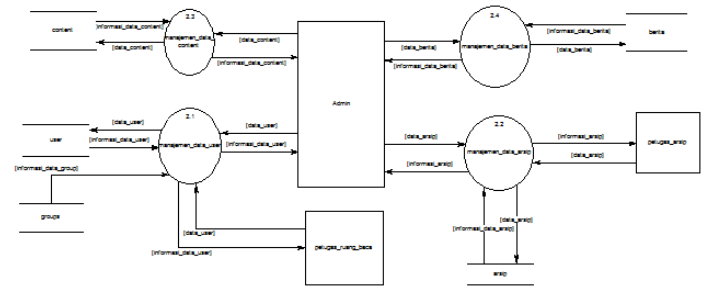

Gambar 7 DFD level 2 Subproses Manajemen Data

Proses Pencarian Arsip dijabarkan menjadi proses Pengindeksan, Penghitungan Bobot, Penghitungan Vektor dan Pencarian Arsip. DFD level 2 subproses Pencarian Arsip dapat dilihat pada gambar 8 .

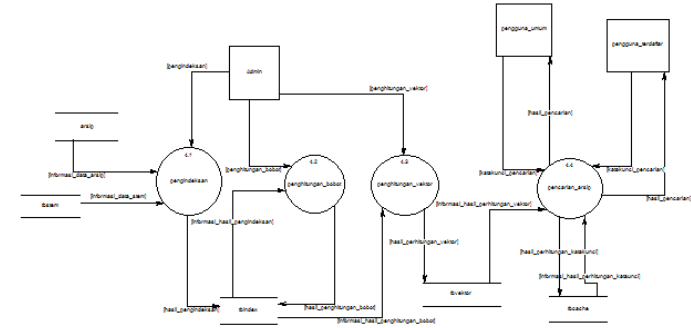

Gambar 8 DFD level 2 Subproses Pencarian Data

\section{IMPLEMENTASI DAN PENGUJIAN Implementasi Antarmuka}

Implementasi antarmuka merupakan hasil dari desain antarmuka yang telah dirancang sebelumnya. Tampilan halaman utama Sistem Informasi Pengelolaan Arsip Statis dapat dilihat pada gambar 9 .

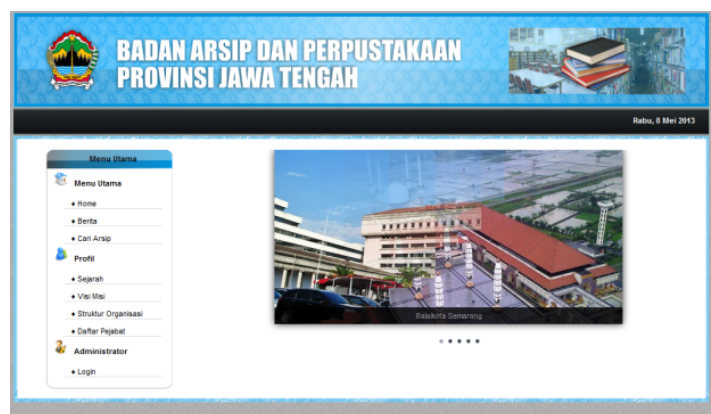

Gambar 9 Tampilan awal Sistem Informasi Pengelolaan Arsip Statis 
Implementasi halaman pencarian pada pengguna terdaftar dapat dilihat pada gambar 10.

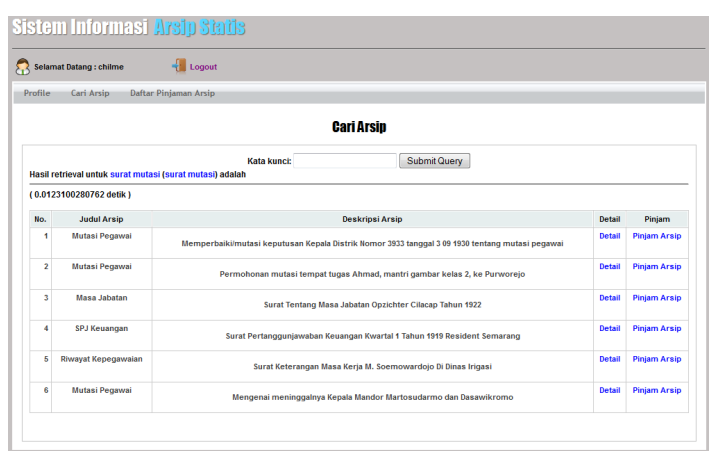

Gambar 10 Halaman Pencarian Arsip

\section{Pengujian}

Pengujian fungsi pencarian arsip menggunakan vector space model dilaksanakan dengan menghitung nilai recall dan precision untuk mengetahui kinerja sistem dalam mencari dokumen yang relevan sedangkan untuk mengukur performa sistem dengan mempertimbangkan aspek keterurutan atau ranking dilakukan penghitungan interpolasi antara recall dan precision. Pengujian menggunakan 75 dokumen arsip statis dengan memasukkan 10 kata kunci yang berhubungan dengan dokumen arsip. Hasil uji penghitungan nilai recall dan precision dapat dilihat dilihat pada tabel 2 .

Tabel 2 Hasil uji penghitungan nilai recall dan precision

\begin{tabular}{|c|c|c|c|c|c|c|}
\hline \multirow{2}{*}{ No } & \multirow{2}{*}{ Kata Kunci } & \multicolumn{2}{|c|}{ Relevan } & \multirow{2}{*}{$\begin{array}{c}\text { Tidak Relevan } \\
\text { Ditemukan }\end{array}$} & \multirow{2}{*}{$\begin{array}{c}\text { Recal } \\
1\end{array}$} & \multirow{2}{*}{$\begin{array}{l}\text { Precis } \\
\text { ion }\end{array}$} \\
\hline & & $\begin{array}{c}\text { Ditemu } \\
\text { kan }\end{array}$ & $\begin{array}{c}\text { Tidak } \\
\text { Ditemukan }\end{array}$ & & & \\
\hline 1 & Permohonan Mutasi & 3 & & 7 & 1 & 0.3 \\
\hline 2 & Permohonan Cuti & 2 & & 7 & 1 & 0.22 \\
\hline 3 & $\begin{array}{l}\text { Anggaran Pemeliharaan } \\
\text { Gedung }\end{array}$ & 9 & 1 & 7 & 0.9 & 0.53 \\
\hline 4 & Permohonan Pensiun & 3 & & 7 & 1 & 0.3 \\
\hline 5 & \begin{tabular}{|l|} 
Laporan \\
Pertanggungjawaban \\
Keuangan \\
\end{tabular} & 10 & & 13 & 1 & 0.77 \\
\hline 6 & Gaji Pegawai & 5 & & 21 & 1 & 0.19 \\
\hline 7 & Serah Terima Jabatan & 1 & & 3 & 1 & 0.25 \\
\hline 8 & Pengangkatan Jabatan & 2 & & 4 & 1 & 0.33 \\
\hline 9 & Penempatan Kerja & 2 & & 6 & 1 & 0.25 \\
\hline 10 & Pemasangan Listrik & 1] & & 1 & 1 & 0.5 \\
\hline & & & & Rata-Rata & 0.99 & 0.364 \\
\hline
\end{tabular}

Berdasarkan hasil pengujian pada tabel 4.3 diperoleh nilai rata-rata recall sebesar 0.99 atau $99 \%$. Nilai tersebut mendekati nilai tertinggi yaitu $100 \%$, sedangkan nilai rata-rata precision sebesar 0.364 atau $36,4 \%$. Hal ini berkaitan dengan jumlah dokumen yang berhasil di indeks. Semakin banyak jumlah dokumen yang berhasil di indeks maka jumlah dokumen yang relevan bisa juga semakin besar dan akan berpengaruh pada nilai recall, namun besar pula jumlah noise (atau dokumen yang tidak relevan), sehingga tingkat precision pun menjadi rendah. Untuk hasil uji penghitungan interpolasi antara recall dan precision dapat dilihat pada tabel 3.

Tabel 3 hasil uji penghitungan interpolasi antara

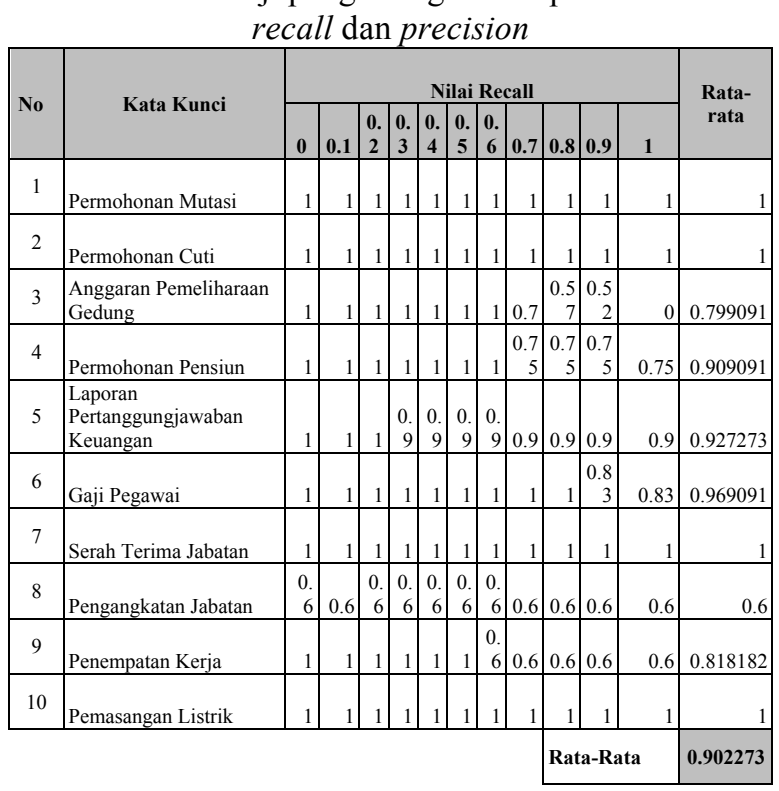

Nilai interpolasi precision pada recall standard ini dirata-ratakan menjadi rata-rata interpolated precision untuk menggambarkan performansi sistem temu kembali informasi. Nilai rata-rata interpolated precision untuk hasil uji coba pada tabel 4.4 menghasilkan nilai sebesar 0,902 atau sebesar 90,2\%.

\section{KESIMPULAN DAN SARAN}

\section{Kesimpulan}

Kesimpulan yang dapat diambil dalam pengerjaan penelitian ini adalah :

1. Dihasilkan sebuah Sistem Informasi Pengelolaan Arsip Statis dengan dilengkapi sistem temu kembali informasi menggunakan vector space model pada Badan Arsip dan Perpustakaan Provinsi Jawa Tengah.

2. Berdasarkan pengujian yang telah dilakukan, Sistem Informasi Pengelolaan Arsip Statis menggunakan vector space model memberikan 
nilai rata-rata recall sebesar $99 \%$. Nilai tersebut mendekati nilai tertinggi yaitu $100 \%$, sedangkan nilai rata-rata precision yang diperoleh sebesar $36,4 \%$.

3. Berdasarkan hasil uji penghitungan nilai interpolasi antara nilai recall dan precision, diperoleh nilai rata-rata interpolasi precision sebesar $90,2 \%$.

\section{Saran}

Untuk pengembangan Sistem Informasi Pengelolaan Arsip Statis selanjutnya perlu ditambahkan fungsi untuk verifikasi KTP agar pendaftaran pengguna dapat dilakukan secara online.

\section{DAFTAR PUSTAKA}

[1] , - , "Indeks dan Pengindeksan”. http://digilib.undip.ac.id/index.php/component/ content/article/53-perpuspedia/189-indeksdan-pengindeksan-, diakses pada tanggal 1 Agustus 2012.

[2] Al Fatta, Hanif, 2007, “Analisis dan Perancangan Sistem Informasi untuk Keunggulan Bersaing Perusahaan dan Organisasi Modern”, Yogyakarta : ANDI.

[3] Bunyamin, Hendra, 2005, "Algoritma Umum Pencarian Informasi dalam Sistem Temu Kembali Informasi Berbasis Metode Vektorisasi Kata dan Dokumen”, Teknik Informatika Fakultas Teknologi Informasi Universitas Kristen Maranatha, Jurnal Informatika, 1 (2).

[4] Bunyamin, H. dan Cathalea P, 2008, “Aplikasi Information Retrieval (IR) CATA dengan Metode Generalized Vector Space Model”, Teknik Informatika Fakultas Teknologi Informasi Universitas Kristen Maranatha, Jurnal Informatika, vol. 4 (1): 29-38.

[5] Christopher D.M., Prabhakar R., and Hinrich S., 2009, "Introduction to Information Retrieval", Cambridge University Press, Cambridge

[6] Herwansyah, Adit, 2009, “Aplikasi Pengkategorian Dokumen dan Pengukuran Tingkat Similaritas Dokumen Menggunakan
Kata Kunci pada Dokumen Penulisan Ilmiah Universitas Gunadarma”, Tugas Akhir, Jurusan Sistem Informasi Fakultas Ilmu Komputer Universitas Gunadarma, Depok.

[7] Jogiyanto, 2005, “Analisis dan Desain Sistem Informasi", Edisi 3, Andi Offset, Yogyakarta.

[8] Karyono, Giat dan Fandy Setyo Utomo, 2012, "Temu Balik Informasi pada Dokumen Teks Berbahasa Indonesia dengan Metode Vector Space Retrieval Model”, Jurnal Seminar Nasional Informasi dan Komunikasi Terapan 2012, Semarang.

[9] Mandala, Rila dan Hendra Setiawan, 2002, "Peningkatan Performansi Sistem Temu Kembali Informasi dengan Perluasan Query Secara Otomatis", Departemen Teknik Teknik Informatika ITB, Bandung.

[10] Pohan, Husni I. dan Kusnassriyanto S.B., 1997, "Pengantar Perancangan Sistem", Erlangga, Jakarta.

[11] Pressman, Roger S, 2001, "Software Engineering : A Practitioner's Approach Fifth Edition”, New York : McGraw - Hill Companies, Inc.

[12] Republik Indonesia, 2009, "Undang-Undang No 43 Tahun 2009 tentang Kearsipan", Lembaga Negara RI tahun 2009, No 152. Sekretariat Negara : Jakarta.

[13] Rusidi, - , "Prosedur dan Teknik Penyusunan Inventaris Arsip Statis", BPAD Provinsi DIY.

[14] Safriadi, Novi dan Ari Wibowo, 2011, "Uji Relevansi dan Performansi Sistem Temu Balik Informasi pada Giggle Search Engine", Teknik Informatika Fakultas Teknik Universitas Tanjungpura, Jurnal ELKHA, vol 3 (2).

[15] Sudayat, Ridwan Iskandar, "Pengertian Sistem Informasi",

http://ridwaniskandar.files.wordpress.com/200 9/05/52-pengertian-sistem-informasi.pdf, diakses pada 17 Maret 2012.

[16] Widodo, Aris P., Djalal E.R., dan Beta N., 2004, "Buku Ajar Basis data”, Jurusan Matematika Fakultas MIPA Universitas Diponegoro. 
Silmi Kafatan, Djalal Er Riyanto, dan Ragil Saputra 